\title{
The Republic of Tatartsan Petrochemical Complex Value Chain Structure Analysis
}

\author{
Safina Aida Anasovna ${ }^{1}$ \\ ${ }^{1}$ Kazan Federal University, 18 Kremlyovskaya str., Kazan, Russian Federation \\ Correspondence: Safina Aida Anasovna. Kazan Federal University, 18 Kremlyovskaya str., Kazan 420008, \\ Russian Federation. E-mail: lenar_s@mail.ru
}

Received: August 24, 2014 Accepted: September 7, $2014 \quad$ Online Published: November 27, 2014

doi:10.5539/ass.v10n24p191

URL: http://dx.doi.org/10.5539/ass.v10n24p191

\begin{abstract}
The aim of this article is to study a redistributive process within a cluster, and the structural analysis of expenses which resulted development of a new model of finished products expenses structure analysis, and the studies of pricing by the main technological conversions on the example of petrochemical complex of the Republic of Tatarstan. It gives an economic assessment of efficiency of a petrochemical complex of the Republic of Tatarstan and quantitative calculation of reserves and the limits of products' cost reduction, as well as it reveals a financial stock of "durability" of a competitive position of a cluster in the region, that is expenses growth potential of the complex which won't cause critical loss of competitive edge. The offered technique promptly and visually analyzes the final product pricing in terms of conversions, and prime cost and profit elements.
\end{abstract}

Keywords: value chain on basic technological conversions, production system on cost structures, manufacturing chain of plastic items production, cost intensity, petrochemical complex

\section{Introduction}

Nowadays the prerequisites of a new wave of economic crisis is observed and actively discussed by scientists and experts, therefore questions of competitive recovery come to the fore again. The behavior of economic units becomes more and more conservative and rational and for this reason management of expenses as well as management of competitiveness becomes more and more actual and important. The petrochemical industry is a key sector of economy of the Russian Federation and the Republic of Tatarstan. Both economic structures of the republic and the federation are similar, that is why studying of cooperation ties of Tatarstan helps to develop effective recommendations both for other regions of the country and for the country on the whole (1).

See the most simplified production chain on the main technological conversions for the Republic of Tatarstan in a petrochemical complex (PCC) in Figure 1.

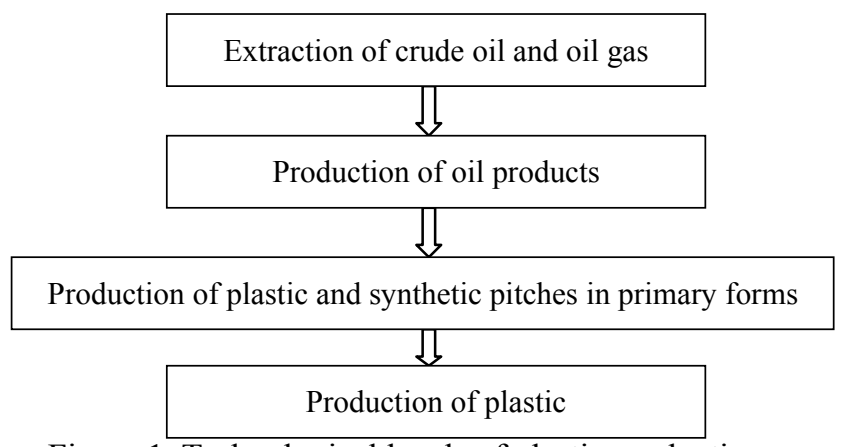

Figure 1. Technological levels of plastic production

The chemistry and petrochemistry of the Republic of Tatarstan takes strategically important main positions in the Russian and world markets. All types of motor fuel (aviation kerosene, automobile gasoline, diesel fuel) are producted in the Republic as well as all valuable types of raw materials for the petrochemical industry. Tatarstan presents $60 \%$ of the Russian polystyrene, $50 \%$ of polyethylene, $31 \%$ of polypropylene, $37 \%$ of synthetic rubbers, 
$30 \%$ of tires, $14 \%$ of detergents (3). Favorable environment in the market of raw materials forms rather steady balanced financial result for foreign trade activities and allows to be actively engaged in investment activity indicated by the stable value appreciation of fixed assets of PCC of the Republic of Tatarstan (4).

The petrochemical complex of the Republic of Tatarstan is presented by about 750 enterprises of the small and medium business which is mostly concentrated in sector of "production of rubber and plastic products" (46\%). Potential of the petrochemical sector increases every year thanks to developing of processing products by the large companies,-polymers, polypropylene glycol, synthetic rubbers, alpha olefins and others.

The 2013 year is disagnated by stagnation of investments and industrial production in Russia. Tatarstan also faced delay of rates of economic growth. Production of petrochemical complex increased at $1.7 \%$ against $8.2 \%$ in 2012. There was a decrease of rubber products and oil products release. At the same time release of petrochemical products, plastic products and oil production is increased.

Annual production rate of work in a petrochemical complex of Tatarstan grew to 10.2 million rubles per a person, the average salary within a complex made 34.3 thousand rubles.

The enterprises of a petrochemical complex of Tatarstan shipped their own goods of production almost on 900 billion rubles in 2013 . There was signed growth of oil processing branches $(+13 \%)$ and oil production $(+2.4 \%)$. Chemical production and production of rubber reduced its revenue by $1 \%$ and $2 \%$ respectively, despite positive dynamics of outputs.

Profit of chemical production decreased at $66 \%$, of rubber production and plastic products- $44 \%$. It is caused by strengthening of the price competition. Last months of the year some petrochemical companies worked at a loss. Oil production profit decreased to $4 \%$ and oil processing decreased $17 \%$. It negatively influenced on contributions to the budget-contributions to the consolidated budget of the republic decreased at $11 \%$ during the year. The added value decreased at 2\% during 9 months of the year 2013.

The largest investments into fixed capital in a petrochemical complex were signed during the last 6 years, in 2013 they grew up at $28 \%$-up to 71 billion rubles. The main growth was provided by "Tatneft", "TAIF-NK", "Ammonium".

It should be noted the increase of petrochemical products import particularly from China. And this production remains competitive even despite a wide haul distance. And after all the considerable part of these goods can be produced in Tatarstan.

Formation of its fifth level, namely-hi-tech processing of plastic (Figure 2) has to be the most significant strategic direction of a production and technological chain development. Hi-tech processing of plastic is a low-cost productio of the wide range of products from high quality, both technological and esthetic, plastic.

The potential demand on available and qualitative plastic in the republic is rather wide. First of all, such demand is based on import substitution of goods: plastic ware, furniture from plastic both for households and for the organizations of public catering and services, toys, etc. Particularly now the use of goods from plastic has a steady tendency in the industry of public catering which is characterized by convenient consumer properties. In the long term such ware can be popular among all establishments of education and health care of the Republic of Tatarstan. Respectively prospective market of such products is rather essential and it is important to activate regional production for ensuring high efficiency of regional social and economic development.

Plastic is also actively used in the industry on production of toys. Such productions occupy a certain niche in economy of many countries and toys production is rather profitable. This subsector of light industry was almost completely stagnated in the first half of 1990 in economy of the Russian Federation having considerably given way to import production, mainly China, with quite poor quality. Meanwhile availability of rather cheap and qualitative plastic in the republic plays big role in competitiveness of such production.

Other direction for ensuring the demand on developing the enterprises of potential fifth level of the production and technological chain is industrial use, particularly for production of vehicles, medical equipment, etc. In this regard developing of small and medium-sized enterprises of the fifth level of the production and technological chain in cooperation with JSC Kamaz, the "Alabuga" industrial enterprises, etc. is quite actual. The problem of providing plastic for the republican industry of Tatarstan must be prioritized.

It should be noted that the Republic of Tatarstan has a sufficient educational and scientific potential for developing the specified fifth level of a production and technological chain. In particular, in Kazan State Technological University (Kazan Chemical and Technological Institution) has educational program of process 
engineers training in the field of plastic production; there are similar specialties at the establishments of secondary and primary professional education.

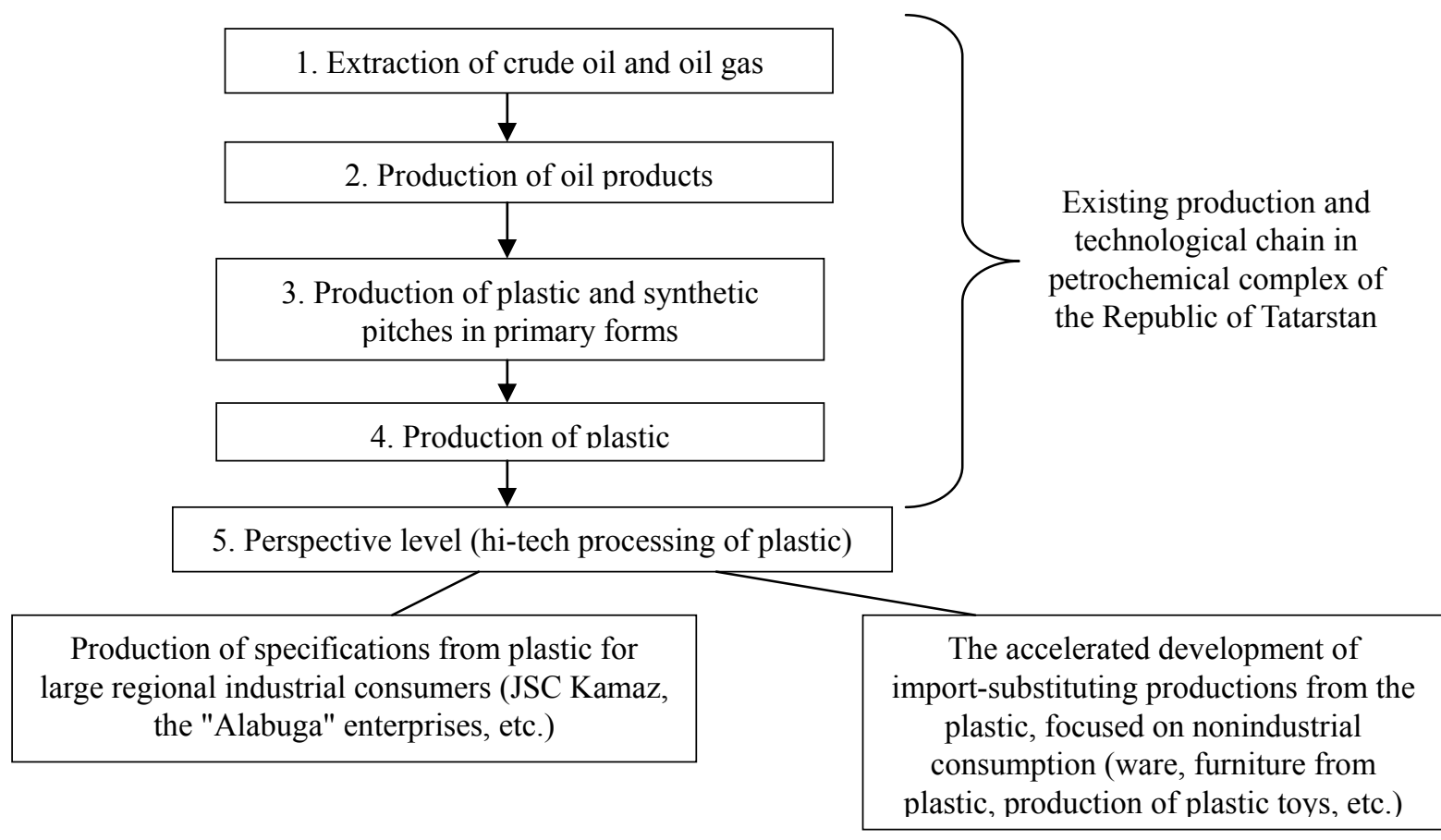

The state assistance to development of the fifth

hi-tech repartition (interest-free rent of the state

areas, preferential leasing of the advanced

equipment, a guarantee on the design credits, etc.)

Figure 2. The directions of development of the fifth level of a production and technological chain (hi-tech processing of plastic) in the Republic of Tatarstan

Production of plastic of both consumer and industrial function is not extremely capital-intensive. So this niche can be filled by small and medium business cooperated with the enterprises of the third and fourth level of the production and technological chain of a petrochemical complex (being developed as affiliated structures for instance).

Economic efficiency of such activity can be reached by decrease of transportation costs as on raw materials delivery and transportation of finished goods to end users; as a result of optimum performance of warehouse economy as close vertical industrial cooperation provides accurate coordination of delivery time of materials and shipment of finished goods up to work on jit system (exact in time) being characterized by minimization of warehouse expenses. Besides the essential factor of potential competitiveness of plastic production is possibility of accurate coordination of quality of production, realization of joint assortment policy, joint financing of research and development in the field of economy and the production technology of products from plastic.

\section{The Technique of the Analysis of the Cost Structure}

As the indicator of expenses for 1 ruble of commercial products is the most adequate for the analysis we will try to interconnect mathematically structural components of cost of the interconnected branches. Summarily the essence of an offered technique of the research lies in calculation of an indicator of a material capacity of production of one technological conversion through the cost intensity of the previous production cycle since the initial raw materials for production of the following product (as a rule, other things being equal) is the previous product. Having carried out decomposition, we group uniform expenses and compare the obtained data with average branch of the previous decomposition and we will make structural research of competitiveness.

As a result we form the following table of basic data. 
Table 1. The initial table of the expenses calculation for 1 rubs of shipped goods volume in 2013. (5)

\begin{tabular}{|c|c|c|c|c|c|c|}
\hline $\begin{array}{l}\text { Type of economic } \\
\text { activity }\end{array}$ & Profit & $\begin{array}{l}\text { Materials } \\
\text { consumption }\end{array}$ & $\begin{array}{l}\text { Cost } \\
\text { intensity of } \\
\text { other costs }\end{array}$ & $\begin{array}{l}\text { Salary } \\
\text { intensity }\end{array}$ & $\begin{array}{l}\text { Cost intensity } \\
\text { of unified } \\
\text { social tax }\end{array}$ & $\begin{array}{l}\text { Deprecation } \\
\text { capacity }\end{array}$ \\
\hline $\begin{array}{l}\text { 4. Crude oil and oil gas } \\
\text { extraction }\end{array}$ & 0.306 & 0.241 & 0.361 & 0.037 & 0.009 & 0.046 \\
\hline $\begin{array}{l}\text { 3. Production of oil } \\
\text { products }\end{array}$ & 0.0223 & 0.8942 & 0.023 & 0.026 & 0.0025 & 0.032 \\
\hline $\begin{array}{l}\text { 2. Production of plastic } \\
\text { and synthetic pitches in } \\
\text { primary forms }\end{array}$ & 0.06 & 0.791 & 0.039 & 0.057 & 0.016 & 0.037 \\
\hline 1. Production of plastic & 0.043 & 0.762 & 0.075 & 0.068 & 0.018 & 0.034 \\
\hline
\end{tabular}

Cost of oil and oil gas production in 2013 in the Republic of Tatarstan amounted 36\% of other expenses which was connected with high level of foreign trade activities. Dynamics of oil and oil gas production expenses growth of the republic is based on growth of the general, material and other inputs and decrease in labor costs and depreciation expenses.

Analyzing the structure of oil production costs it should be noted that these foreign trade activities occupy the highest level of costs (material inputs borrow the main share of expenses). Despite it one of competitive advantages of the republic is the low share of labor expenses.

Production of plastic and synthetic pitches in primary forms (this foreign trade activity is a subspecies of "Chemical production") has also high level of expenses but differs a smaller material capacity in comparison with production of oil products and incurs big labor costs which are firstly connected with the high average number of the personnel in this area.

In structure of cost of foreign trade activities "Production of plastic products" material inputs prevail. It must be noted high level of labor expenses in the ratio with the highest average number of workers of foreign trade activities on a cluster and the smallest indicators of an average monthly salary.

We express a material capacity of production of plastic through a cost intensity of production of plastic and synthetic pitches in primary forms as initial raw materials for production of plastic is polyethylene. Pay attention to profit of production of plastic and synthetic pitches in primary forms (5). So, we receive the following equality:

$$
0.762=0.06 * 0.762+0.791 * 0.762+0.039 * 0.762+0.057 * 0.762+0.016 * 0.762+0.037 * 0.762
$$

The main objective of this action (1) consists in clarification of a share of a cost intensity of production of the previous level of a chain in a share of a material capacity of the subsequent level. Thus, we multiply a material capacity of foreign trade activities "Production of plastic" on all elements of structure of prime cost and profit of foreign trade activities "Production of plastic and synthetic pitches in primary forms", thereby visually we see a contribution of each element to the cost of raw materials of more hi-tech production (in this case polyethylene as raw materials for production of plastic and plastic products).

$$
0.762=0.04572+0.602742+0.029718+0.043434+0.012192+0.028194
$$

We note that cost of 1 rub of volume of the shipped goods is taken for calculation therefore each sum of elements of expenses on levels is respectively equal to one. Now we will substitute in the first equality $1=0.043+0.762+0.075+0.068+0.018+0.034$ (structure of expenses and profit of Production of plastic products according to table 2) instead of a material capacity of the plastic (0.762), expressed through a cost intensity and polyethylene profit (2), и получим следующее:

$$
1=0.043+\underbrace{0.04572+0.602742+0.029718+0.043434+0.012192+0.028194}_{0.762}+0.075+0.068+0.018+0.034
$$

So, we expressed a material capacity of plastic products (0.762) through elements of cost of polyethylene.

In the same way we express a material capacity of polyethylene through a cost intensity, received in 1 formula, and ethylene profit as the main raw materials for production of polyethylene ethylene serves. 


$$
\begin{aligned}
& 0.602742=0.0223 * 0.602742+0.8942 * 0.602742+0.023 * 0.602742+ \\
& 0.026 * 0.602742+0.0025 * 0.602742+0.032 * 0.602742
\end{aligned}
$$

We can notice that the material capacity share to a level of production of oil products decreases $(0.791$ 0.602742), as expenses of the following levels are added at each level:

$$
0.602742=0.01344147+0.538972+0.013863+0.015671+0.001507+0.019288
$$

Considering the first, second and third levels, our equality in which plastic is expressed by ethylene, looks as follows:

$$
\begin{aligned}
& 1=0.043+0.04572+0.013441147+0.538972+0.013863+0.015671+0.001507+ \\
& 0.019288+0.029718+0.043434+0.012192+0.028194+0.075+0.068+0.018+0.034
\end{aligned}
$$

We note that the profit of the 1st level remains initial (0.043), the profit of the 2nd level 0.04572 is transferred to an element of a material capacity of the 1st level (formula 3), the profit of the 3rd level is transferred to an element of a material capacity of the 2nd level respectively (0.013441147), as well other elements of cost of appropriate levels, except a material capacity.

Then we express a material capacity of production of oil products through a cost intensity of oil production (7).

$$
\begin{aligned}
& 0.538972=0.306 * 0.538972+0.241 * 0.538972+0.361 * 0.538972+0.037 * 0.538972+ \\
& 0.009 * 0.538972+0.046 * 0.538972
\end{aligned}
$$

Total equality characterizes all structure of a chain consisting of four levels. In this case a material capacity of plastic being expressed through an ethane cost intensity that is a material capacity of ethylene is expressed through ethane (8) cost intensity.

\begin{tabular}{|c|c|c|c|c|c|c|c|c|c|c|c|c|}
\hline $\begin{array}{l}\text { Type of } \\
\text { economic } \\
\text { activity }\end{array}$ & Profit & & $\begin{array}{l}\text { Material } \\
\text { capacity }\end{array}$ & & $\begin{array}{l}\text { Cost } \\
\text { intensity } \\
\text { of other } \\
\text { costs }\end{array}$ & & $\begin{array}{l}\text { Salary } \\
\text { intensity }\end{array}$ & & $\begin{array}{l}\text { Cost } \\
\text { intensity } \\
\text { of } \\
\text { unified } \\
\text { social } \\
\text { tax }\end{array}$ & & $\begin{array}{l}\text { Deprication } \\
\text { capacity }\end{array}$ & \\
\hline $\begin{array}{l}4 . \\
\text { Production } \\
\text { of plastic }\end{array}$ & 0.043 & + & & + & 0.075 & + & 0.068 & + & 0.018 & + & 0.034 & + \\
\hline $\begin{array}{l}3 . \\
\text { Production } \\
\text { of plastic } \\
\text { and } \\
\text { synthetic } \\
\text { pitches in } \\
\text { primary } \\
\text { forms }\end{array}$ & 0.04572 & + & & + & 0.029718 & + & 0.043434 & + & 0.012192 & + & 0.028194 & + \\
\hline $\begin{array}{l}2 . \\
\text { Production } \\
\text { of oil } \\
\text { products }\end{array}$ & 0.013441147 & + & & + & 0.013863 & + & 0.015671 & + & 0.001507 & + & 0.019288 & + \\
\hline
\end{tabular}

$$
\begin{aligned}
& 1=0.043+0.04572+0.013441147+0.1649254+0.129892+0.194569+0.019942+0.004851+ \\
& 0.024793+0.013863+0.015671+0.001507+0.019288+0.029718+0.043434+0.012192+ \\
& 0.028194+0.075+0.068+0.018+0.034
\end{aligned}
$$

\section{Results}

More visually this production system is displayed in table 2 where uniform expenses are grouped in columns.

Table 2. The Republic of Tatarstan petrochemical complex value chain structure calculations results developed in 2013 


\begin{tabular}{|c|c|c|c|c|c|c|c|c|c|c|c|c|}
\hline $\begin{array}{l}\text { Type of } \\
\text { economic } \\
\text { activity }\end{array}$ & Profit & & $\begin{array}{l}\text { Material } \\
\text { capacity }\end{array}$ & & $\begin{array}{l}\text { Cost } \\
\text { intensity } \\
\text { of other } \\
\text { costs }\end{array}$ & & $\begin{array}{l}\text { Salary } \\
\text { intensity }\end{array}$ & & $\begin{array}{l}\text { Cost } \\
\text { intensity } \\
\text { of } \\
\text { unified } \\
\text { social } \\
\text { tax }\end{array}$ & & $\begin{array}{l}\text { Deprication } \\
\text { capacity }\end{array}$ & \\
\hline \multirow[t]{2}{*}{$\begin{array}{l}1 . \\
\text { Extraction } \\
\text { of crude } \\
\text { oil and oil } \\
\text { gas }\end{array}$} & 0.1649254 & + & 0.129892 & + & 0.194569 & + & 0.019942 & + & 0.004851 & + & 0.024793 & $=1$ \\
\hline & 0.267086547 & & 0.129892 & & 0.31315 & & 0.147047 & & 0.03655 & & 0.106274 & $\begin{array}{l}\text { The } \\
\text { sum on } \\
\text { columns }\end{array}$ \\
\hline
\end{tabular}

The indicator of cumulative profit in structure of a value chain makes $26.7 \%$, and the large profit is made by branches "Extraction of oil and oil gas" and "Production of plastic and synthetic pitches in primary forms" 0.165 and 0.046 , respectively, that makes $61.8 \%$ and $17.2 \%$ of cumulative profit. In production structure of expense for basic raw materials-ethane makes $13 \%$, when its profit is of $26.7 \%$ that confirms high profitability of this branch. As for other expenses, it is possible to note that they have very high specific weight in structure of a value chain (5). also make $31.3 \%$, in comparison with other indicators of expenses take leading positions (for comparison this element of prime cost in the West European countries makes only 14-17\%). More than a half of uniform other expenses is occupied "Extraction of oil and oil gas" (62.3\%). Labor expenses make only 14.7\% in structure of cumulative labor expenses of a cost chain where "Production of plastic products" has the highest rate of labor expenses in uniform structure of expenses- $46.3 \%$ and, respectively occupies the highest rate of expenses for the unified social tax (UST) (49.2\%). Depreciation expenses in an analyzed production system occupy $10.6 \%$ among which $32 \%$ is occupied by foreign trade activities "Production of plastic".

\section{Discussion}

It is known that one of the most authoritative methods of research of intersectoral communications and proportions is the intersectoral balance (input-output) (6). However this method is the extremely laborious from the view of collecting primary information and its systematization. So, the latest intersectoral balance (ISB) of Russia was made in 2003 year (7). A rule of thumb states that this technique is bounded for research of branches and mesobranches. Nowadays there is no corresponding statistics allowing to calculate intersectoral balance even at the level of the region, the mesoeconomy in our country.

\section{Conclusion}

The maintenance of this technique of the analysis of elements of revenue of all production chain allows to reveal a share of expenses in revenue of production of petrochemical production on the main technological conversions, to reveal a financial stock of "durability" for the purpose of receiving larger profit, and also visually reflects interrelation of types of economic activity of PCC from the view of expenses and profits. Owing to the detection of these features companies plan financial result expenses and the corporate prices and the State forms industrial and financial policy correctly.

Thus, considering this circumstance, it is more expedient to use a newly developed model of the analysis of structure of a value chain on the main technological conversions of branch for studying the redistributive process in a cluster, and also for the structural analysis of expenses.

\section{References}

Bagautdinova, N. G., Nayda, A. M., Hayrullin, B. A., \& Arzhantseva, N. (2014). Behaviour of Households on Financial Investments Market. Mediterranean Journal of Social Sciences, 5(12), 103-106.

Gafurov, I. R., Safiullin, M. R., \& Safiullin, A. R. (2012). Analysis of structural ruptures of competitiveness of petrochemical productions of the Republic of Tatarstan. Kazan: Publishing house of Kazan Federal University.

Khadiullina, G. N., Bagautdinova, N. G., Shevko, N. R., \& Pratchenko, O. V. (2014). Condition and Development Characteristics of The Russian Market of Information Technilogies. Mediterranean Journal of 
Social Sciences, 5(12), 21-26.

Panasyuk, M. V., Pudovik, E. M., \& Sabirova, M. E. (2014). Problems of labor market of modern Russia in conditions of stable economic growth. Life Science Journal, 11(6s), 487-489.

Safina, A. A. (2012). Formation of a production and technological chain of PCC in the conditions of innovative economy of the Republic of Tatarstan. Economic messenger of the Republic of Tatarstan, (4), 75-83.

Safiullin, M. R., Eflova, M. Y., \& Nagimova, A. M. (2012). Social moods and self-identification of middle class in Tatarstan. Sotsiologicheskie issledovaniya: Web of Knowledge (Scopus), (10), 28-33.

Safiullin, M. R., El'shin, L. A., \& Shakirova, A. I. (2012). Evaluation of business and economic activity as a short-term forecasting tool. Herald of the Russian academy of sciences, 82(4), 290-294. http://dx.doi.org/10. $1134 / \mathrm{S} 1019331612040053$

Safiullin, M. R., Safiullin, A. R., Ermolaeva, P. O., \& Noskova, E. P. (2013). Interdisciplinary Approach to the Analysis of the Competiteveness Types of the Economic Activities Based on the Example of the Oil and Gas Industry (Republic of Tatarstan Case). Middle-East Journal of Scientific Research, (18), 42-49.

Sarkin, A. V., Bagautdinova, B. G., Khadiullina, G. N., Averyanov, B. A., \& Arzhantseva, N. (2014). Development of Paternalistic Strategy of Industrial Growth with Regard to Institutional Traps (Qwerty-Effects). Mediterranean Journal of Social Sciences, 5(12), 49-54.

Sarkin, A. V., Bagautdinova, N. G., Averyanov, B. A., \& Arzhantseva, N. (2014). The Consept of "New" Paternalism and Its Realisation within the State Regualtion of Econom. Mediterranean Journal of Social Sciences, 5(12), 27-32.

Sarkin, A. V., Bagautdinova, N. G., Averyanov, B. A., Novenkova, A. Z., \& Arzhantseva, N. (2014). Assessment of Efficiency of Realization of Paternalistic Policy of Industrial Enterprises Development. Mediterranean Journal of Social Sciences, 5(12), 9-14.

System of tables "Expenses-release" in Russia 2003. (2006). Moscow: Federal State Statistics Service publishing house.

Vasiliy, L. (1997). Intersectoral economy: Preface. Scientific editor and author of the preface is academician of the Russian Academy of Sciences A.G. Granberg; Translation from English (pp. 19-20). Moscow: Economics.

\section{Copyrights}

Copyright for this article is retained by the author(s), with first publication rights granted to the journal.

This is an open-access article distributed under the terms and conditions of the Creative Commons Attribution license (http://creativecommons.org/licenses/by/3.0/). 